\title{
BIBLIOTECAS Y DESIGUALDAD SOCIAL: EXPLORANDO EL ESTADO DEL ARTE ${ }^{1}$
}

\author{
Natalia Duque Cardona* \\ Escuela Interamericana de Bibliotecología. Universidad de Antioquia. \\ Viviana Mazón Zuleta** \\ Escuela Interamericana de Bibliotecología. Universidad de Antioquia.
}

\begin{abstract}
Resumen: El artículo tiene como propósito presentar el estado del arte realizado para el proyecto de investigación doctoral La incidencia de la biblioteca en la reducción de las desigualdades sociales: el caso del sistema de bibliotecas públicas de la ciudad de Medellín a partir del Acuerdo 079 de 2010. El texto presenta una introducción general del estado del arte, posterior a ello se presenta la metodología de búsqueda realizada, para dar lugar a la presentación de los conceptos previos: biblioteca y desigualdad social; así como los conceptos emergentes. A continuación, se plantean las diversas disciplinas y sus aportes en el tema de biblioteca y desigualdad social, dando paso a los enfoques teóricos rastreados en el estado del arte. Finalmente, el artículo cierra con las tendencias y hallazgos generales en el campo de la biblioteca y la desigualdad social.
\end{abstract}

Palabras clave: Bibliotecas; sociedad; desigualdad social; estado del arte.

Title: LIBRARIES AND SOCIAL INEQUALITY: EXPLORING STATE OF THE ART.

Abstract: The article aims to present the state of the art made for the Doctoral research project The impact of the library on reducing social inequalities: The case of the System of Public Libraries of the city of Medellin from Agreement 079 of 2010. The text presents a general introduction of the state of the art, after which the research methodology is presented, to give rise to the presentation of the previous concepts: library and social inequality; As well as emerging concepts. The different disciplines and their contributions in the subject of library and social inequality are presented below, giving way to the theoretical approaches traced in the state of the art. Finally, the article closes with trends and general findings in the field of library and social inequality.

Keywords: Libraries; society; social inequality; state of art.

Copyright: (C) 2018 Servicio de Publicaciones de la Universidad de Murcia (Spain). Este es un artículo de acceso abierto distribuido bajo los términos de la licencia Creative Commons Reconocimiento 4.0 Internacional (CC BY 4.0).

\section{INTRODUCCIÓN Y CONTEXTUALIZACIÓN}

Este artículo tiene como propósito presentar una revisión de la literatura producida en el campo de la bibliotecología social, y específicamente de los temas bibliotecas y desigualdad social; este se realiza a través de un método de análisis documental crítico enmarcado en un proceso de formación doctoral que alimenta el estado del arte de la investigación: La incidencia de la biblioteca en las desigualdades sociales: el caso del sistema de bibliotecas públicas de la ciudad de Medellín a partir del Acuerdo 079 de 2010.

Se comienza con una breve presentación de la descripción de las fuentes, materiales y métodos usados para el desarrollo de la revisión de la literatura. Posterior a ello se presenta el apartado de resultados, el cual se organiza en cinco partes: conceptos previos, conceptos emergentes, aportes disciplinares, enfoques metodológicos y tendencias, vacíos y hallazgos. A continuación, se introducen los conceptos previos, es decir aquellos identificados como relevantes inicialmente y que fueron los insumos primarios en la revisión bibliográfica: biblioteca y desigualdad social. Posteriormente, se desarrolla el apartado nombrado conceptos emergentes; en este se presenta el concepto de ciudadanía, que fue recurrente en la literatura consultada. A continuación, se propone seguir con la exposición de cómo y cuál ha sido el aporte de diversas disciplinas en el tema de la biblioteca y la desigualdad social. Finalmente, se exponen los enfoques teóricos y metodológicos desarrollados por los autores en la temática indagada, para dar cierre a la revisión se culmina con las Conclusiones: tendencias, vacíos del conocimiento y hallazgos generales del campo estudiado.

\footnotetext{
*natalia.duque@udea.edu.co

***viviana.mazon@udea.edu.co

Recibido: 15-03-2017; $2^{\mathrm{a}}$ versión: 22-01-2018; aceptado: 25-01-2018.
}

DUQUE CARDONA, N. y MAZÓN ZULETA, V. Bibliotecas y desigualdad social: Explorando el estado del arte. Anales de Documentación, 2018, vol. 21, nº 1. Disponible en: http://dx.doi.org/10.6018/analesdoc.21.1.289021. 


\section{MATERIALES Y MÉTODOS}

El ejercicio de revisión bibliográfica se ubica en un paradigma constructivista y crítico de acuerdo con las propuestas de Guba y Lincoln desarrolladas en su Handbook of Qualitative Research (1994), donde conciben el paradigma como un sistema de creencias básicas basados en supuestos ontológicos, epistemológicos.

El paradigma constructivista en cuanto en su dimensión ontológica plantea que las realidades son aprehensibles bajo las formas de construcciones mentales múltiples, construcciones que son modificables, así como sus realidades asociadas. La dimensión epistemológica supone que el investigador y el objeto de la investigación están interactivamente ligados para que los "hallazgos" sean literalmente creados a medida que sucede la investigación. La distinción convencional entre ontología y epistemología desaparece en este paradigma al igual que en el crítico. Por último, la dimensión metodológica propone que la naturaleza variable y personal de las construcciones sociales sugiere que construcciones individuales solo pueden suscitarse y refinarse a través de una interacción entre el investigador y las fuentes. Estas construcciones diversas son interpretadas utilizando técnicas convencionales hermenéuticas, y son comparadas y contrastadas a través de un intercambio dialéctico. El fin último es el de destilar una construcción consensual que es más informada y sofisticada que ninguna de las construcciones anteriores (incluyendo por supuesto la construcción ética del investigador).

Ahora bien, el paradigma crítico está presente en la revisión bibliográfica en su dimensión ontológica, ya que este supone que una realidad que es aprehensible, alguna vez fue plástica, pero con el paso del tiempo fue moldeada por un conjunto de factores sociales, políticos, culturales, económicos, étnicos y de género, que luego se cristalizaron en una serie de estructuras que ahora son (inapropiadamente) tomadas por "reales", es decir naturales e inmutables. De otro lado en su dimensión epistemológica, el investigador y el objeto investigado son considerados como ligados interactivamente, con los valores del investigador (y de los "otros" situados) afectando inevitablemente la investigación. Por tanto, los hallazgos están mediados por valores. Y por último la dimensión metodológica implica que la investigación posee una naturaleza transaccional que requiere un diálogo entre el investigador y los sujetos de la investigación; ese diálogo debe ser de naturaleza dialéctica para transformar la ignorancia y los equívocos (la aceptación de las estructuras mediadas históricamente como inmutables) en una conciencia mejor informada o como lo dice Giroux (1988) "como intelectuales transformativos".

Ambos paradigmas posibilitan la comprensión de la biblioteca y su relación con la sociedad a través de un análisis documental crítico que permite identificar los diversos factores políticos, sociales y culturales que inciden en la biblioteca.

Las fuentes permiten un estudio que establece relaciones para comprender cómo se articulan las partes de un todo, en este caso de la biblioteca con la sociedad, con la desigualdad social. De este modo el método usado para la revisión bibliográfica posibilita identificar el sustento teórico de la biblioteca, como dispositivo, en relación con las funciones sociales que esta posee y la desigualdad social. Este método implica el análisis, síntesis, deducción e inducción de la información a través del relacionamiento de las categorías fundamentales del proyecto de investigación.

\section{DESCRIPCIÓN DE FUENTES}

La elección de las fuentes está ligada con criterios que permitieron realizar la búsqueda de bibliografía en diversos sitios y repositorios. Para ello se tienen en cuenta referentes conceptuales, procedimentales y disciplinares. El punto de partida de la revisión sistemática es el problema y la pregunta de investigación del proyecto doctoral, los cuales permiten identificar conceptualmente categorías de búsqueda.

$\begin{aligned} & \text { Problema de investigación } \\
& \text { Incidencia de la biblioteca en las desigualdades sociales. }\end{aligned}$
\begin{tabular}{|l|l|l|}
\hline Preguntas & $\begin{array}{l}\text { ¿Cuál es la incidencia de la biblioteca en } \\
\text { las desigualdades a través de las prácticas de búsqueda } \\
\text { de la lectura, escritura y oralidad que esta } \\
\text { implementa? }\end{array}$ & $\begin{array}{l}\text { Besigualdad social } \\
\text { Lectura }\end{array}$ \\
\hline & $\begin{array}{l}\text { ¿Cómo contribuye la biblioteca a la } \\
\text { reducción de las desigualdades sociales } \\
\text { en las comunidades? }\end{array}$ & \\
\hline
\end{tabular}

Tabla I: Problema de investigación, preguntas y categorías de búsqueda. 
Una vez identificadas las categorías conceptuales, se recurrió a tesauros especializados ${ }^{2}$ en el campo de la sociología y la bibliotecología, con el propósito de contar con un lenguaje controlado que permitiera realizar diversas ecuaciones de búsqueda, para contar con mayor asertividad en la ubicación de registros. En estas se realizó el rastreo de artículos en relación con el tema general de investigación: Bibliotecas y desigualdad social. Posterior a ello y partiendo de las preguntas de investigación y las categorías conceptuales propuestas a lo largo del proyecto de investigación se realizaron diversas búsquedas, algunas de ellas generales, las cuales dieron muy pocos resultados y otras centradas en las categorías principales, haciendo uso de ecuaciones de búsqueda que permitieran acceder a información contextualizada para el proyecto, por lo cual la categoría de biblioteca siempre estuvo presente.

Por último, se indagaron fuentes alternativas, que no forman parte del círculo de información científica y académica legitimada, no obstante, son parte fundamental de los desarrollos en el campo de estudio, por lo cual se incluyen materiales en Creative Commons y algunos blogs.

La revisión sistemática permitió recuperar 54 registros asociados a bases de datos, 42 registros en repositorios y 27 registros en fuentes alternativas. Esto es un primer indicio para indicar que el problema de desigualdad social y biblioteca es una temática estudiada en el campo de la vida cotidiana, es decir que en algunas ocasiones los resultados de indagaciones en el tema no son publicadas en revistas indexadas o canales de circulación formal de la investigación científica como se observa en la búsqueda bibliográfica. De los materiales encontrados, se realizó una selección de los que alimentarían el estado del arte de la investigación partiendo de su vínculo directo con la exploración, los saberes disciplinares y los objetivos a los que aporta.

Una vez seleccionados los materiales que hacen parte del estado del arte se procedió con el diseño de un instrumento que facilitara una lectura crítica y permitiera analizar la incidencia social que ha tenido la biblioteca en el campo de las desigualdades sociales. Para ello se tomó como referente la propuesta del artículo Revisión y análisis documental para estado del arte: una propuesta metodológica desde el contexto de la sistematización de experiencias educativas (Barbosa Chacón; Barbosa Herrera y Rodríguez Villabona, 2003).

\section{EXPOSICIÓN DE RESULTADOS. CONCEPTOS PREVIOS}

La revisión sistemática realizada de la literatura, a partir de la temática biblioteca y desigualdad social, permitió una lectura y análisis de conceptos previos, que son fundamentales para la comprensión del tema.

\subsection{La biblioteca}

Para identificar el modo en que esta categoría es abordada por diferentes estudiosos, se realizó una matriz donde los propósitos de la biblioteca propuestos por los autores, se agrupan de acuerdo a las funciones sociales de la biblioteca. Y, a su vez, estas se cruzan con las formas de nombrar la biblioteca encontrada en la bibliografía explorada. Este ejercicio permitió identificar nueve alternativas de comprensión de la biblioteca como institución social.

\begin{tabular}{|c|c|c|c|c|c|c|}
\hline & Lugar/propósito & Espacio & Dispositivo & Agencia & Órgano & $\begin{array}{l}\text { Aparato } \\
\text { ideológico }\end{array}$ \\
\hline \multirow{7}{*}{$\begin{array}{l}\text { Funciones } \\
\text { culturales } \\
\text { simbólicas }\end{array}$} & $\begin{array}{l}\text { Perpetuación del capital } \\
\text { cultural }\end{array}$ & & $\mathbf{X}$ & & & $\mathbf{X}$ \\
\hline & Producir sentidos & & $\mathbf{X}$ & & & \\
\hline & $\begin{array}{l}\text { Conservación del capital } \\
\text { cultural }\end{array}$ & & $\mathbf{x}$ & & & \\
\hline & Mediación cultural & $\mathbf{X}$ & & & & \\
\hline & $\begin{array}{l}\text { Recibir la memoria y los } \\
\text { bienes culturales }\end{array}$ & $\mathbf{X}$ & & & & \\
\hline & $\begin{array}{l}\text { Difundir la memoria y los } \\
\text { bienes culturales }\end{array}$ & $\mathbf{X}$ & & & & \\
\hline & Recuperación de la memoria & $\mathbf{X}$ & & & & \\
\hline
\end{tabular}




\begin{tabular}{|c|c|c|c|c|c|}
\hline & y los bienes culturales & & & & \\
\hline & $\begin{array}{l}\text { Conservación de la memoria } \\
\text { y los bienes culturales }\end{array}$ & $\mathbf{X}$ & & & \\
\hline \multirow{2}{*}{$\begin{array}{l}\text { Funciones } \\
\text { educativas } \\
\text { formativas }\end{array}$} & Formación de ciudadanía & $\mathbf{X}$ & & & \\
\hline & $\begin{array}{l}\text { Formación de lectores y } \\
\text { escritores }\end{array}$ & $\mathbf{X}$ & & & \\
\hline \multirow{3}{*}{$\begin{array}{l}\text { Funciones } \\
\text { políticas o de } \\
\text { ciudadanizaci } \\
\text { ón }\end{array}$} & $\begin{array}{l}\text { Construcción } \quad \text { de } \quad \text { la } \\
\text { ciudadanía }\end{array}$ & $\mathbf{X}$ & & & $\mathbf{X}$ \\
\hline & $\begin{array}{l}\text { Controlar y mantener el } \\
\text { orden social }\end{array}$ & & & $\mathbf{X}$ & $\mathbf{X}$ \\
\hline & $\begin{array}{l}\text { Construcción de la vida } \\
\text { pública }\end{array}$ & & $\mathbf{X}$ & & $\mathbf{X}$ \\
\hline
\end{tabular}

Tabla II: Formas de nombrar la biblioteca de acuerdo con sus funciones sociales.

Enmarcada en las funciones culturales o simbólicas que tiene la biblioteca, esta puede ser entendida como:

- Dispositivo para perpetuar y conservar el capital cultural: La idea de entender la biblioteca a partir de la categoría habitus ${ }^{3}$ de Bourdieu, es retomada por Riveros Guerrero, Salamanca y Moreno Torres (2012) de las ideas de Urbizagástegui (1992), poniendo de manifiesto cómo esta institución se ha encargado de albergar y seleccionar el capital cultural legitimado en la sociedad, dejando de lado saberes como los ancestrales y conservando el habitus. Lo anterior, se refleja, por ejemplo, en el acceso a que provee la biblioteca a una población particular y ciertas fuentes de información, aquellas que dialogan con el capital cultural que esta alberga. Es así como en los usuarios de la biblioteca, categorías asociadas con diversidad cultural, sexual, entre otras, no son visibles. Así como la cultura oral.

- Dispositivos productores de sentidos: Al igual que Riveros Guerrero, Salamanca y Moreno Torres, retoman el concepto de habitus, para generar comprensiones de la biblioteca como dispositivo, Rasteli y Cavalcante (2014) en Mediação cultural e apropriação da informação em bibliotecas públicas, se hacen de la categoría dispositivo para pensar en las bibliotecas como instrumentos de gestión cultural.

Esta perspectiva es muy potente, una vez que las bibliotecas se entienden como "dispositivos productores de sentidos, que permiten el acceso a la información, observando la estructura de significados vivenciados en la investigación, lectura, literatura en general, los eventos culturales y de contacto con las artes (...) así como la participación activa y colectiva de individuos" (Rasteli y Cavalcante, 2014, p. 53). Es importante resaltar, que en este campo el profesional se identifica como un animador cultural y agente cultural, no como profesional de la información. Además, la comprensión de las prácticas asociadas a la lectura implica el acto de apropiarse del conocimiento, a través de diversas culturas asociadas no solo a la cultura escrita.

A diferencia de la postura de Riveiros y Salamanca (2012), en este caso la idea de dispositivo esta propuesta como un ejercicio de disidencia que implica la diversa producción de sentidos, de acuerdo al contexto y las prácticas culturales de las comunidades, es decir, de acuerdo a la relación de los sujetos con la biblioteca, no como perpetuador de un saber particular, sino como espacio para la construcción local y consonante con el territorio y la historia local.

- Espacio para la mediación cultural: Rasteli y Cavalcante (2014), promueven la comprensión de la biblioteca a través de las prácticas de lectura y escritura que en esta se desarrollan. Para ellos, la biblioteca es una institución cuya esencia reside en la cultura y, por tanto, es un lugar para la producción artística, un espacio que articula diferentes experiencias que promuevan la apropiación cultural de y en las comunidades. De acuerdo con las disertaciones de los investigadores, la biblioteca puede ser considerada una acción afirmativa, en cuanto los sujetos se apropien de ella y movilizan acciones en su interior y en comunidad, pues su rol no es solo pasivo.

Su tesis y comprensión de la biblioteca como espacio para la mediación cultural, implica el reconocimiento de la importancia de "promover el contacto entre sujetos, generando canales de comunicación que permitan estimular sensaciones, sentidos o sentimientos, o que se den a través del lenguaje de una cultura o por la misma cultura" (p. 45) Esta mediación cultural, se da entonces a través del reconocimiento de la biblioteca como un espacio para la convergencia de la diversidad cultural. 
- Espacio para la recepción, difusión y conservación de la memoria y los bienes culturales: Arévalo (2012) en su artículo El patrimonio como representación colectiva: la intangibilidad de los bienes culturales, plantea la posibilidad de entender la biblioteca fuera de la idea de dispositivo que controla y perpetúa los bienes culturales. Así, el autor retomando ideas de la producción de sentidos y comprensiones de la realidad propiciadas través de la mediación cultural dada en la biblioteca; propone a la institución como un espacio para el reconocimiento, recepción, conservación y difusión de la cultura. De este modo, en las disertaciones de Arévalo, son relevantes los bienes culturales que cobija la biblioteca, y las cualidades que en estos residen.

Enmarcada en las funciones educativas o formativas que tiene la biblioteca esta puede ser entendida como:

- Espacio para la formación ciudadana: Jaramillo y Quiroz (2013) retoman los planteamientos de la educación social para pensar y proponer modos de contribuir a la formación ciudadana en la biblioteca pública, entendiéndola como "una manera de consolidar procesos que posibiliten cambios de actitudes y aptitudes, de prácticas sociales capaces de aceptar la pluralidad desde el reconocimiento político, cultural y normativo, para que el sujeto comprenda, valore, encuentre un sentido y así participe en los procesos de construcción de ciudadaní; procesos educativos configuradores y potenciadores de ambientes de libertad, tolerancia y de acuerdos normativos posibilitadores de prácticas ciudadanas" (p. 142).

- Así mismo, Álvarez (2003, p. 58) plantea que la biblioteca es un espacio potente para "la formación ciudadana (...) entendida como un trabajo de intervención sociocultural y educativa dirigido a impulsar un cambio en las representaciones y prácticas de la ciudadanía que una sociedad tiene. Dicho de otra manera, se representa a la formación ciudadana como un campo comprometido con el impulso de la reflexión, la revalorización, la transformación y la construcción de los sentidos, idearios y prácticas de la ciudadanía, para así generar cambios en las personas, en sus contextos y en sus interacciones".

- Espacio para la formación de lectores y escritores: El bibliotecólogo Didier Álvarez (2003), en su investigación Una aplicación a las propuestas de formación ciudadana de la Escuela de Animación Juvenil, plantea los diversos lenguajes políticos de la lectura, y cómo estos han permeado las prácticas de formación de lectura y escritura en las bibliotecas. Dando lugar a comprender la dimensión pedagógica de la biblioteca, lo anterior lleva a reconocer que la formación está ligada con espacios diferentes a los institucionalizados (escuela, colegios, universidades).

La comprensión de la biblioteca como espacio para la formación de lectores y escritores es una posibilidad de explicitar la intencionalidad de la lectura y la escritura, y la ausencia de prácticas orales en esta institución. Así mismo de hacer consciente los discursos, e intencionalidades, que subyacen a la necesidad de pensar en formar lectores y escritores.

Es así como la propuesta de Álvarez (2003), es una oportunidad para la disertación en cuanto a la potencialidad que posee la biblioteca en el campo de formación, y las claridades que esta debe tener al momento de promover las propuestas de lectura y escritura, pues dependiendo de ello y de acuerdo con las propuestas puede convertirse en un dispositivo que perpetúa el capital cultural o en uno productor de diversos sentidos.

Enmarcada en las funciones políticas o de ciudadanización que tiene la biblioteca esta puede ser entendida como:

- Órgano de control y regulación del orden social: Riveros, Salamanca y Moreno Torres (2012) ponen en discusión, retomando ideas de Urbizagástegui (1992) cómo la biblioteca dependiendo del tipo de materiales que alberga, puede generar procesos de control y regulación social. Ya que esto implica la promoción y divulgación de un capital cultural específico, asociado a un tipo de sociedad que se quiere conseguir.

Es así como la biblioteca se convierte, en términos de democratización, en un órgano para el fortalecimiento del capital cultural y ejercicio de la ciudadanía, en un lugar carente de sentido, en una institución que controla y regula, de acuerdo a los lineamientos e intereses de las élites. En palabras de Riveros, Salamanca y Moreno Torres (2012, p. 9) "la biblioteca misma se ve reducida a un mecanismo de dominio de las clases privilegiadas en la perpetuación de un orden social excluyente $e$ inequitativo. La contradicción inherente a la instrumentalización del discurso de la modernidad no es ajena a una biblioteca pública que no reflexiona sobre los conceptos y las prácticas que moviliza, y esta misma biblioteca se hace culpable cuando, siendo consciente de esta contradicción, no actúa consecuentemente ni toma parte efectiva en su neutralización”.

Entender la biblioteca como órgano de control y regulación del orden social, es hacer explícita la relación que existe entre el acceso al capital cultural y la forma en que este implica la construcción de tejido social. De acuerdo con las comprensiones e historias que los sujetos conozcan, se generan diversos tipos de relaciones entre ellos.

- Agencia para la construcción de la vida pública: Toro Peña, en su trabajo Las bibliotecas públicas como instituciones de integración social (2014), parte del reconocimiento de la categoría de subjetividad colectiva 
propuesta por Hugo Zemelman, en la cual los procesos de autorreferencia, carácter colectivo de la subjetividad, procesos volitivos, resistencia, plano de la posibilidad y aspectos instituyentes, contribuyen a la integración de los sujetos a la esfera pública, a su participación en la sociedad a través de su agenciamiento a esta institución.

De este modo la biblioteca "se puede considerar como agencia que puede operar en los procesos subjetivos de su entorno, en tanto es responsable y tiene la capacidad y los recursos (colecciones, espacios de discusión) para construir cultura política, para contribuir en el fortalecimiento del poder de los grupos sociales locales y para generar perspectivas de lo político desde una visión crítica del contexto mundial y local en la que opera" (Toro Peña, 2014, p. 99).

- Aparato ideológico: Meneses Tello (2008c), plantea la relación existente entre bibliotecas e ideología, argumentando "que este tipo de instituciones culturales desarrollan, organizan, conservan y difunden conocimiento ideológico en el seno del Estado, puesto que el contenido de sus acervos refleja intereses de los grupos sociales antagónicos" (p. 15).

Es así como en el marco de las funciones políticas o de ciudadanización la biblioteca estaría fortaleciendo un orden social específico de acuerdo con la ideología que se encuentre en el poder. Este hecho presenta una fuerte relación de la dupla biblioteca-poder como lo expone Meneses Tello. Es así que las funciones culturales y políticas se encuentran intrincadas, en cuanto a través de la instauración de cierto capital cultural se instaura lo ideológico.

En palabras de Meneses Tello (2008d), "Se sabe que no existe grupo social o Estado hegemónico que pueda asegurar durante largo tiempo su poder político solo con el poder represivo, pues la cultura cumple una función social-ideológica fundamental para el sostén y reproducción del sistema político. Así que, los grupos dominantes ejercen la función de dirección cultural de transmisión ideológica a través de un conjunto de organizaciones e instituciones que divulgan la interpretación de la realidad correspondiente a sus intereses, entre ellas las de carácter bibliotecario".

Como cierre al concepto de biblioteca revisado y los modos de enunciarla identificados, es importante exponer que los diversos modos de nominación son un primer aporte a la propuesta de investigación, una vez que permiten identificar los propósitos asociados a esta institución social. La mayor implicación que revela el tratamiento de este concepto en la literatura del tema, es el dejar explícito que la biblioteca responde a intereses que la superan, independiente de cuáles sean, lo cual implica que esta es un actor antecedido de una ideología y lenguajes políticos que direccionan su ser, saber y hacer.

Asimismo, es relevante plantear que los debates presentados respecto a la biblioteca son emergentes; estos retoman ideas clásicas, no obstante, hacen énfasis en discusiones de tipo político, pedagógico y cultural con mayor profundidad. La comprensión de la biblioteca como dispositivo cultural es un elemento que potencia la pregunta de investigación, una vez esta tiene importantes implicaciones en la conservación del capital cultural y del habitus, conceptos relacionados con el tema de la desigualdad social que a continuación se aborda. Además, que procura una comprensión sociológica de la biblioteca en relación con dinámicas asociadas a la desigualdad. Esta perspectiva, relación con las funciones sociales de la institución, es decir en diálogo con algunos elementos de la biblioteca como institución social, pueden posibilitar y potenciar el tema de estudio.

\subsection{Desigualdad social}

El concepto de desigualdad social, se encuentra implícito en todos los documentos abordados, aunque en pocos de ellos abordados de modo explícito. Esta se entiende como las construcciones sociales que implican la ausencia de condiciones para funcionar plenamente como seres, hombres y mujeres, en palabras de Göran Therborn "la desigualdad es una diferencia que viola algunos supuestos normales (mundanos) de la igualdad (no necesariamente de manera explícita o evidente) (...) por tanto, las desigualdades son violaciones de los derechos humanos, que impiden a miles de millones de personas alcanzar un desarrollo humano pleno (2015b, p. 49).

Específicamente, y de acuerdo con la propuesta de este sociólogo sueco para las tipologías de la desigualdad; en el campo de las bibliotecas identificamos dos tipos:

- Desigualdad existencial: relacionada con la desigualdad personal de autonomía, dignidad, grados de libertad y de derecho al respeto y al desarrollo personal.

- Desigualdad de recursos: que impide a los actores humanos disponer de recursos similares para desenvolverse.

Estas tipologías se identifican en prácticas de exclusión ${ }^{4}$ y jerarquización ${ }^{5}$, los cuales son mecanismos de desigualdad. En las bibliotecas su presencia es reiterativa, de modo particular en la comprensión de la biblioteca como: órgano de control y regulación del orden social, dispositivo para perpetuar y conservar el capital cultural y dispositivo productor de sentidos.

Al igual que con el concepto de biblioteca, se planteó una matriz donde se retoman los modos de nombrar la biblioteca, donde el tema de la desigualdad social es más pronunciado. Estos modos de nombrarla se cruzan con los 
tipos y mecanismos de desigualdad social propuestos por Therborn, y se identifica cuáles de estos se dan de acuerdo con el modo de nombrar la biblioteca. Posterior a la matriz se plantea el modo en el que la desigualdad se manifiesta de acuerdo a sus propósitos y funciones.

\begin{tabular}{|c|c|c|c|c|c|}
\hline & \multirow[b]{2}{*}{$\begin{array}{l}\text { Modo de nombrar la } \\
\text { biblioteca }\end{array}$} & \multicolumn{2}{|c|}{ Tipo de desigualdad } & \multicolumn{2}{|c|}{ Mecanismo de desigualdad } \\
\hline & & Existencial & Recursos & Jerarquización & Exclusión \\
\hline \multirow{2}{*}{$\begin{array}{l}\text { Funciones culturales } \\
\text { o simbólicas }\end{array}$} & $\begin{array}{l}\text { Órgano de control y } \\
\text { regulación del orden } \\
\text { social }\end{array}$ & $\mathbf{X}$ & $\mathbf{X}$ & $\mathbf{X}$ & $\mathbf{x}$ \\
\hline & $\begin{array}{l}\text { Dispositivo para } \\
\text { perpetuar y conservar el } \\
\text { capital cultural }\end{array}$ & $\mathbf{X}$ & & $\mathbf{X}$ & $\mathbf{X}$ \\
\hline \multirow{2}{*}{$\begin{array}{l}\text { Funciones políticas o } \\
\text { de ciudadanización }\end{array}$} & $\begin{array}{l}\text { Dispositivo productor } \\
\text { de sentidos }\end{array}$ & $\mathbf{X}$ & & $\mathbf{X}$ & $\mathbf{X}$ \\
\hline & Aparato ideológico & $\mathbf{X}$ & & $\mathbf{X}$ & $\mathbf{X}$ \\
\hline
\end{tabular}

Tabla III. Tipos y mecanismos de desigualdad en las bibliotecas según sus funciones sociales.

- Órgano de control y regulación del orden social: en esta categoría la biblioteca actúa como institución que ordena y, por tanto, compone el tejido social, de acuerdo a una jerarquización relacionada con el acceso a la cultura escrita. Así mismo promueve procesos de exclusión, pues de acuerdo con la idea de biblioteca se controla a quienes acceden a ella, se regula el modo de ser y comportarse en este espacio.

- Dispositivo para perpetuar y conservar el capital cultural: Retomando nuevamente la idea de la biblioteca como institución que mantiene el acceso a cierto tipo de cultura, generalmente en relación con la idea de cultura occidental, vemos cómo Meneses Tello (2010) plantea la relación cultura-civilización-sociedad, reconociendo la biblioteca como una "institución radical al tratar temas de comprensión de la cultura, la civilización, los seres humanos civilizados, asociado con una cultura letrada. Así, el nexo bibliotecas y cultura cobra una importancia particular para el estudio de la unidad sociedad y bibliotecas porque estos centros reflejan la cultura material e intelectual de la sociedad (p. 124)".

Es así como el considerarlas espacios centrados para las élites y la cultura escrita exclusivamente da cuenta de un tipo de cultura. Uno de los puntos principales trabajados por Tello, el pensar y reflexionar cómo en esa relación biblioteca-sociedad puede hacerse un análisis gnoseológico acerca de la incidencia de los distintos tipos de biblioteca y su relación con el cambio de las estructuras sociales.

Los mecanismos tanto de jerarquización como de exclusión se hacen presentes. Se excluye todo lo que no haga parte de una cultura occidental y al mismo tiempo se jerarquiza a través de relaciones de sub-ordinación y supra-ordenación, como también lo propone Civallero (2006b) en sus disertaciones al referirse al lugar preponderante que posee la escritura en relación con la oralidad.

Asimismo se promueven relaciones de desigualdad tanto existenciales como de recursos, no obstante, el tema de los recursos es relevante una vez que el acceso a cierta idea de cultura está limitada, controlado por la idea de cultura y de biblioteca que se promueve, como lo expresa Riveros, Salamanca y Moreno (2012) "En esta perspectiva, los procesos de educación formal, y en muchas ocasiones las instituciones públicas, incluida la biblioteca pública, contribuyen a perpetuar la línea divisoria entre las clases dominantes y las clases menos favorecidas, debido a que sus objetivos se centran en mantener el sistema social reinante por medio de la consecución de programas institucionales que no modifican sustancialmente esa situación” (p. 13) o en palabras de Urbizagásteguí: "las bibliotecas son aparatos ideológicos del Estado, legitimados como espacios públicos abiertos para todos, pero donde las clases dominantes realizan sus habitus (...) transformándose por esta acción, en aparatos ideológicos de la clase Estado" (1992, p. 40).

- Dispositivo productor de sentidos: La biblioteca entendida en esta lógica puede implicar tanto mecanismos de desigualdad, como mecanismos de inclusión y des-jerarquización, puesto que como perpetúa cuenta con la posibilidad de generar otras alternativas. Por ejemplo, en la investigación de Toro Peña (2014), la biblioteca es una agencia de procesos socioculturales. En esta se presenta como la comprensión de la dimensión institucional 
de la biblioteca, genera el reconocimiento de esta como "una institución fuertemente integrada a los procesos culturales de los barrios" (p. 97), lo cual promueve procesos de inclusión y des-jerarquización, de organización colectiva y reconocimiento.

Así mismo, en la dimensión subjetiva de la biblioteca pública, se halla "una carga simbólica agenciada desde la auto reflexividad facilitando las interpretaciones y sentidos que permiten a los sujetos configurar su identidad política, el carácter colectivo a partir del cual se producen reflexiones compartidas sobre sí mismos y sobre la problemática que comparten, genera una pertenencia, un nosotros, los procesos volitivos: donde se establecen reivindicaciones como que los barrios sigan siendo lo que han sido hasta el momento, que las adecuaciones administrativas del Estado no borren el legado cultural e histórico que representan" (p. 99).

Civallero (2004) propone, por ejemplo, la posibilidad de comprensión de la biblioteca como productor de sentidos a través de la formulación de modelos teóricos aplicables a comunidades como las indígenas.

- Aparato ideológico: La biblioteca entendida en esta perspectiva se relaciona con la desigualdad existencial en cuanto la autonomía personal, los grados de libertad y el desarrollo personal tienen alcances de acuerdo con la ideología en que se enmarque la propuesta bibliotecaria y por supuesto se evidencia en los propósitos de las prácticas de lectura y escritura que en la institución se realicen, puesto que el acceso a la información es uno de los principales mecanismos de emancipación o subyugación.

$\mathrm{Y}$ en el marco de la desigualdad de recursos se explicitan en cuatro puntos específicos, propuestos por Meneses Tello: el problema ideológico en la selección-eliminación-destrucción de materiales, la traza ideológica en el ordenamiento bibliográfico, la postura del bibliotecólogo ante el problema de las ideologías y el bibliotecólogo a la luz del servicio bibliotecario que presta en la arena de las luchas ideológicas. Los anteriores en relación con los materiales, colecciones, servicios que la biblioteca posee y pone al servicio de acuerdo con las posturas ideológicas que adopta, en relación con prácticas libertarias o de censura asociadas a los recursos bibliotecarios. "la conexión entre el proceso de seleccionar libros con algunos acontecimientos o nociones de carácter ideológico, se refleja claramente cuando entra en colisión la libertad de leer con el fenómeno de la censura" (Meneses, 2005, p. 66).

En el campo del ordenamiento, habría que empezar por decir que "un sistema de clasificación bibliotecaria no es simplemente una tabla de números. Está obligado a reflejar el conocimiento ideológico de las diferentes clases sociales" (Meneses, 2013c, p. 124), y dependiendo de este se da el acceso al conocimiento, la apropiación social del mismo y por tanto se incrementa o disminuye la desigualdad de recursos.

A modo de conclusión, en relación con la categoría de desigualdad social es imperante destacar la ausencia de la función social económica o productiva de la biblioteca, lo cual evidencia que la correlación de la biblioteca con conceptos como el de desigualdad social está dada a partir de una comprensión sociológica articulada con la cultura y la política, mas no partiendo de la perspectiva clásica que define la desigualdad social con base en una comprensión de redistribución económica. Por ello es relevante el desarrollo de la desigualdad social a partir de una perspectiva sociológica.

\section{CONCEPTOS EMERGENTES}

El concepto de ciudadanía está presente de modo explícito y reiterativo en la mayoría de las fuentes consultadas, aun cuando la concepción de biblioteca no está ligada exclusivamente con sus funciones políticas o de ciudadanización, se hace evidente que la existencia de la biblioteca implica necesariamente la presencia de un ciudadano, de un sujeto de derechos y obligaciones. No obstante, la discusión se daría partiendo de la comprensión de ciudadanía asociada con la comprensión misma de la biblioteca.

A continuación, se trabajan los modos en que los autores plantean la ciudadanía en el marco de la biblioteca, y en relación con los modos identificados para nombrar la biblioteca.

Otras ciudadanías, es una idea que puede discutirse a la luz de los planteamientos de Civallero (2006), en las disertaciones que él realiza al plantear como la construcción de este concepto en "Latinoamérica en general, y en Argentina en particular, el pensamiento positivista-evolucionista del siglo XIX buscó borrar las particularidades culturales regionales, especialmente las aborígenes, abiertamente calificadas de "salvajes", pretendiendo lograr, de este modo, ciudadanos "civilizados" de acuerdo al modelo ideal europeo o estadounidense" (p. 53) y como es necesario pensar en la biblioteca la reivindicación de otras ciudadanías, la deconstrucción de esta idea puesto que en el caso de comunidades indígenas, por ejemplo, en algunos países, los pueblos indígenas no pueden apelar a la Declaración Universal de Derechos Humanos (DUDH) por no considerárseles ciudadanos plenos, sino sujetos de estatutos especiales, o sea, el equivalente a un menor de edad (p. 87). 
Ciudadanía cooperante, es la propuesta de Alejos Aranda (2013) en su disertación Dimensiones de la biblioteca pública: inclusión social desde el Sistema Nacional de Biblioteca en Perú. La investigadora expone cómo el ejercicio de la ciudadanía, en una biblioteca pública, se evidencia en la capacidad que tienen los sujetos de reconocer su propia identidad, en el reconocimiento de los sujetos dentro de un proceso de construcción de proyectos colectivos, y escenarios de vida, de nación y de mundo (p. 133).

Ciudadano educado e informado es la idea en que Meneses Tello (2013b), hace énfasis en la importancia de un sujeto que siempre pueda ejercer libremente el pensamiento, sea capaz del cuestionamiento de dogmas y la difusión del conocimiento, hombres y mujeres capaces de formar sus juicios y opiniones sobre la base de la razón (p. 330). Es así como el rol de la biblioteca en la construcción de ciudadanía radica en "la garantía y el acceso del uso de la información” (p. 325), para toda la sociedad, para los más necesitados en oportunidades, para los más vulnerables.

Ciudadanía crítica, es una propuesta desarrollada por la investigadora Orlanda Jaramillo (2013), esta expone como la biblioteca pública puede ser entendida como lugar para la construcción de ciudadanía, a partir del lente de la educación social. En este caso la ciudadanía tiene implicaciones como la protección de los derechos fundamentales y colectivos. En la convivencia, la participación y la autonomía. Así, las prácticas que se viven en el interior de la biblioteca están en pro de la convivencia; el buen trato, respeto, diálogo, confianza y cuidado del bien público), en la participación expresada en la puesta por ser, hacer y tomar parte (sentidos de identidad, pertenencia y apropiación) y la autonomía, comprendida como el reconocerse (reconocer al otro, deliberar y decidir sobre asuntos propios del entorno) (p. 141). Es así como la investigadora propone que la biblioteca con una postura política clara, puede contribuir en su hacer a la formación de sujetos críticos, autónomos y participativos.

Ciudadanía republicana, que, como plantea Álvarez (2003), sea un sujeto “adosado y respetuoso de la tradición referida a un summum de ideas, representaciones y sentidos de la vida y el hombre muy bien recogidas y promovidas por el canon" (p. 32).

Ciudadanía que cuestione, Álvarez (2003) retoma la idea de una ciudadanía centrada en un lenguaje político crítico emancipatorio que, en espacios como la biblioteca "reconozca la lectura y la escritura como acatos de emancipación, por tanto, la ciudadanía sería un proceso de alfabetización crítica "es decir, a la habilitación política de las personas desde la base de la recuperación de su memoria y de su voz históricas. Se trata de permitir la asunción de la ciudadanía como un acto de cuestionamiento de las hegemonías que han determinado el orden social injusto y excluyente. Leer y escribir son, en consecuencia, prácticas para la participación, el impulso de la inclusión social y política de las personas y facilitadoras del autogobierno".

\section{APORTES DISCIPLINARES- BIBLIOTECAS Y DESIGUALDAD SOCIAL}

Ahora bien, después de desarrollar las categorías iniciales y emergentes se plantea como diversas disciplinas de las ciencias humanas y sociales han aportado a la discusión de la biblioteca y desigualdad social. Partiendo de reconocer que, al ser la bibliotecología, una disciplina social y humanística eminentemente empírica ha recurrido a otras áreas para fortalecer sus desarrollos epistémicos.

Este tema de investigación ha sido estudiado a partir de la década de los cincuenta aproximadamente, no obstante, la época de mayor producción respecto al tema se ha centrado en el siglo XXI. Este hecho puede estar asociado, a la reflexión respecto a la biblioteca que se comenzó a dar en la antigua Unión Soviética, con los trabajos realizados por Ogan Chubarian (1976), así como los desarrollos norteamericanos de Jese Shera (1962, 1970, 1990) y Margareth Egan (1955) y posteriormente Landheer (1970). Asimismo, las disertaciones de Panda y Ranganathan (1987) en la India.

En la década de los 90 y comenzado el siglo XXI, se observa una importante producción bibliográfica en el campo de las bibliotecas y sociedad proveniente de Argentina, Brasil, México, Colombia, Cuba y Perú. Así como discusiones en el ámbito europeo particularmente en España. Es probable que el surgimiento del grupo Modernidad/colonialidad en Latinoamérica haya contribuido a movilizar la discusión en este campo, puesto que las desigualdades sociales son una categoría relevante en este marco analítico.

Es importante resaltar aportes de la bibliotecología anglosajona, la cual retoma algunos desarrollados desde la perspectiva de la justicia social, centrada en la igualdad de oportunidades y derechos humanos, los desarrollos en esta perspectiva se centran en la redistribución de recursos, lo cual plantea un campo de desarrollo en perspectiva del reconocimiento, y por supuesto de una relación dialéctica entre ambos para la comprensión de la biblioteca y su rol social. "Reconocimiento se ha convertido en una palabra clave de nuestro tiempo. Esta idea, una venerable categoría 
de la filosofía hegeliana, resucitada no hace mucho por los teóricos políticos, está resultando fundamental en los trabajos para conceptualizar los debates actuales acerca de la identidad y la diferencia. [...] Si la relevancia del reconocimiento es, en la actualidad, indiscutible, su relación con la 'redistribución' sigue a falta de un tratamiento teórico suficiente" (Fraser, 2006, p. 13).

Asimismo, desarrollos enfocados en la desigualdad vista desde una perspectiva económica en relación con el acceso a las bibliotecas e información, de acuerdo a distinciones socio económicas: ricos y pobres, sin embargo, el desarrollo asociado al reconocimiento en relación con la diversidad cultural está poco desarrollado aún. En lo anterior se destacan trabajos como Levin (2000), Pateman y Vicent (2010), Muddiman (2000). Es así como el trabajo de la biblioteca desde una perspectiva del reconocimiento con un enfoque sociológico y de los estudios culturales está en aras de fortalecerse.

Para el análisis de los trabajos estudiados en relación con el tema de investigación, se identificaron las áreas del saber que influyen en las disertaciones abordadas. Esta decisión corresponde al reconocimiento de la bibliotecología como una disciplina cuya fundamentación epistemológica está en fortalecimiento, lo cual implica que la comprensión social de la biblioteca recurra a diversos saberes para su comprensión. En la revisión bibliográfica se destaca los aportes de la ciencia política, los estudios culturales, la sociología, la pedagogía y la historia. Gran parte de los trabajos estudiados cuentan con material empírico donde se establece una relación del campo discursivo con el práctico.

En el campo de la ciencia política se destaca el trabajo Riveros Guerrero, Salamanca y Moreno Torres (2012), Lectura y biblioteca pública: perspectivas sociales en el discurso de la modernidad, los autores exponen "la función social de la biblioteca pública y las prácticas de lectura que allí se adelantan, en relación con la problemática de la instrumentalización, característica de los discursos racionales de la modernidad, y la incidencia de esta en el discurso social bibliotecario. Se reflexiona sobre el concepto de ciudadanía en el marco de esta instrumentalización, haciendo énfasis en las disposiciones de los organismos multilaterales para el desarrollo de la labor bibliotecaria en los países latinoamericanos" (p. 7). La reflexión propuesta por los investigadores, tiene un campo empírico donde se materializan las propuestas y es en la optimización de los servicios de la Red de Bibliotecas Públicas de Bogotá, entre los años 2009-2011.

Los investigadores, señalan un punto importante en el tema investigativo y es la escasa rigurosidad al momento de pensar la función social de la biblioteca, pues sus prácticas se han retomado de un modelo occidental, asociado con la cultura escrita preponderantemente, que ha funcionalizado la tarea de la institución "Es evidente un vacío conceptual en la definición de la función social de la biblioteca pública y del papel que allí se le asigna a la lectura, y remite a la escasez de reflexiones conceptuales sobre el compromiso social de la biblioteca y sobre la manera como la promoción de la lectura contribuye a su consecución" (2012, p. 10).

De otro lado, Toro Peña (2014), realiza un estudio de caso en una de las bibliotecas públicas de BiblioRed, en Bogotá, Colombia. La indagación parte de una pregunta sobre la necesidad de explicar el lugar de las bibliotecas en las sociedades latinoamericanas. Abordando el modo cómo las bibliotecas públicas en contextos populares pueden agenciar procesos de subjetividad colectiva a partir de sus servicios bibliotecarios. Se plantea un análisis sobre estas bibliotecas como agencias de construcción de la esfera pública, aquí es relevante el tema del rol social y político de la biblioteca pública. Metodológicamente, el estudio de Toro Peña recurre a las teorías de la subjetividad y la subjetividad colectiva de Hugo Zemelman, se construye alrededor de la categoría de subjetividad colectiva un instrumento, que permite explorar en las narrativas subjetivas de los usuarios, elementos para describir procesos agenciados en la biblioteca pública.

Esta necesidad de indagar, y preguntarse por las bibliotecas, casa adentro, lleva a relacionar desarrollos de las Ciencias Humanas y Sociales, específicamente de la Ciencia Política, para retomar el concepto de lo público en el campo de la biblioteca. Este hecho podría posibilitar, una comprensión más amplia de las funciones sociales de la biblioteca, y no ligadas exclusivamente con los intereses del Estado. Lo cual implica preguntarnos: ¿cómo las bibliotecas públicas influyen en los procesos subjetivos de la sociedad civil? ¿De qué modo estas contribuyen a la construcción y fortalecimiento del tejido social?

De igual modo, Meneses Tello (2013a), en su artículo Bibliotecas y política: el paradigma político de la biblioteca pública, analiza la función de ciudadanización de la biblioteca pública, poniendo en discusión el mito apolítico de la biblioteca a través del debate de cuatro factores políticos: el gubernamental, el ciudadano, el electoral y el revolucionario. El investigador presenta como "la esencia de la biblioteca es netamente política, pues la institución no es ajena al desarrollo y a la consolidación de esta institución de lectura pública en el seno de la sociedad" (p. 2). Asimismo, se realza el componente ideológico presente en la institución bibliotecaria y su intención aparente de 
mostrarse neutral. La presencia y reconocimiento de discursos ideológicos en la biblioteca, implica exponer públicamente a qué propósitos contribuye socialmente, en términos de desigualdades sociales específicamente, qué rol juega la institución.

Este modo de plantear la biblioteca y, por supuesto, la práctica al interior de esta, es vital puesto que de acuerdo con Meneses (2013a) "en los Estados capitalistas las bibliotecas públicas coadyuvan ordinariamente al control social, puesto que su objetivo político general, acordado desde las esferas de la política cultural del Estado, es controlar el acceso a la información y, por ende, los hábitos de lectura del pueblo, para así, asegurar que tenga este las habilidades necesarias que apunten a perpetuar el sistema social capitalista. (...) En este sentido, esta naturaleza de biblioteca es producto también de la acción política del pueblo lector".

Un aporte fundamental en el campo de la Ciencia Política de Meneses Tello (2008), está en relación con el desarrollo de una teoría política para las instituciones bibliotecarias, específicamente una bibliotecología política.

Y en consonancia con los discursos ideológicos a los que responden las bibliotecas, en Colombia, Didier Álvarez (2003), ha realizado un importante trabajo en el campo del relacionamiento entre la Ciencia Política y la biblioteca, al preguntarse por los lenguajes políticos que subyacen a la lectura y la escritura. Al respecto el autor plantea la existencia de tres discursos: funcional liberal, republicano y crítico-emancipatorio. Cada uno de ellos responde a intereses particulares en relación con el tipo de sociedad deseada, lo cual implica un reconocimiento del poder colonial de las prácticas de lectura y escritura.

De otro lado, el mexicano Muela Meza (2006) realiza un análisis crítico a la disciplina bibliotecológica, no solo en su fundamentación epistemológica sino también en su praxis, esto debido al modo de encarar las funciones sociales inherentes a la profesión y a la institución bibliotecaria. Para subsanar ese vacío, el autor intenta abordar el fenómeno de la ética en las responsabilidades sociales retomando un análisis conceptual crítico, integral y evolutivo materialista que intente abarcar y triangular en un todo analítico nociones tanto de las humanidades (e.g. filosofía, literatura), de las ciencias del espíritu (e.g. bibliotecología, sociología) y de las ciencias naturales (e.g. biología, neuropsicología).

La discusión que promueve la Ciencia Política en relación con el statu quo de la biblioteca en la sociedad y los poderes que allí coexisten históricamente, lleva a pensar la influencia que esto tiene en el campo de la cultura. Para ello los estudios culturales, desarrollan en el campo bibliotecario la relación de la memoria, el patrimonio, la confrontación de la cultura escrita con la oral en las colecciones y prácticas. Brasil, Perú y Argentina, han sido países con grandes aportes en este campo.

El discurso brasileño influenciado por las teorías de mediación cultura y la educación popular de Paulo Freire ha tenido relevancia. En estos desarrollos la biblioteca se ha comprendido como un dispositivo productor y receptor de bienes culturales, como espacios de construcción del conocimiento, conservación y recuperación de la memoria. Los aportes relevantes en este campo se observan en la propuesta de Mota, Cavalcante y Feitosa (2014), donde la memoria juega un papel fundamental, no obstante, Mendlovic Pason (2014), en su artículo ¿Hacia una nueva época en los estudios de la memoria social?, propone un recorrido por el concepto en el campo de la vida cotidiana y en el ámbito académico. Ya la investigadora, comienza a realizar una intersección del trabajo de la memoria con las instituciones y lugares, lo cual es un terreno fértil al momento de pensar la biblioteca.

En relación con la cultura, Arévalo (2012), tiene entre otros, los propósitos de exponer el modo en el que la cultura adquiere formas diversas a través del tiempo y del espacio. De entender cómo la protección y promoción de la diversidad de las expresiones culturales presuponen el reconocimiento de la igual dignidad de todas las culturas. Es así como Arévalo propone, a partir de la antropología social, el desarrollo de la noción de tradición, bienes culturales intangibles y representación de la memoria social.

El trabajo desarrollado por Alejos Aranda, retoma la reflexión que en el campo de la sociología ha ocupado la bibliotecología y son sus dimensiones o funciones sociales. Esta lo hace a través de un estudio de caso Inclusión social desde el sistema nacional de bibliotecas en el Perú, en el trabajo se reitera la existencia de las dimensiones sociales de la biblioteca, así como la posibilidad de entenderla como un espacio propicio para la inclusión social, donde se incluyan a grupos históricamente desatendidos. No obstante, es de anotar que el trabajo posee una perspectiva multicultural, asociada a las nociones de integración e igualdad, dejando de lado el tema de la equidad y contribuyendo a perpetuar el capital cultural de ciertas comunidades.

De otro lado, Edgardo Civallero, bibliotecólogo argentino, se ha dedicado a realizar una importante producción académica en torno a la reflexión de la biblioteca y los saberes ancestrales, así como la posibilidad de pensar 
propuestas alternativas a la biblioteca pública que conocemos tradicionalmente, planteando como principio, la función de recuperación, conservación protección y difusión de la cultura que posee la biblioteca. De este modo Civallero tiene como categorías principales en sus propuestas el patrimonio cultural, la oralidad, la identidad y la aculturación, diversidad e individualidad. En su trabajo Quebrando el silencio, bibliotecas, archivos y tradición oral (2006), presenta la narración del lado de los vencidos, de los colonizados y pone de cara como la preeminencia de una única historia ha implicado el olvido de la oralidad y por tanto de diversos relatos de gran riqueza, cultura e historia. Así mismo en Guardianes de la fragilidad: bibliotecas públicas, patrimonio intangible y diversidad cultural, plantea como premisa el "interés manifiesto de esferas internacionales, por convertir a la biblioteca pública en un recinto de recuperación y difusión de saberes, incluyendo los más tradicionales o aquellos que por sus características han sido generalmente olvidados" (2005, p. 6).

Así mismo Civallero, expone el caso de la Casa de las palabras (2004), el cual es una experiencia argentina para pensar la biblioteca con comunidades indígenas, en su disertación retoma propuestas de la educación intercultural bilingüe, así como ideas pertenecientes a las "nuevas" corrientes de pensamiento de la bibliotecología, movimientos alternativos etiquetados bajo el rótulo común de "bibliotecología progresista. En Tradición oral indígena en el sur de América Latina: los esfuerzos de la biblioteca por salvar sonidos e historias del silencio (2007), presenta el trabajo en el NE de Argentina (2001-2006), que incluyó el desarrollo de colecciones sonoras en pequeñas bibliotecas generadas en escuelas de poblaciones indígenas. Tales fondos sonoros recuperaron tradición oral comunitaria y la conectaron con las actividades escolares. El material grabado y algunas de sus transcripciones escritas permitieron recuperar un fragmento del patrimonio cultural de la comunidad y emplearlo en diferentes servicios.

La preocupación de Civallero lo ha llevado, como se mencionó anteriormente, al desarrollo en el campo del patrimonio, lo cual implica un trabajo directo con la oralidad, en su trabajo Las voces sin voz: oralidad y centros de conservación de la memoria (2004), el autor plantea la dicotomía entre oralidad y escritura, rescatando la importancia de los nichos orales y su relevancia en la recuperación de la palabra, resaltando como las bibliotecas y archivos tienen una deuda histórica en la recuperación, conservación y difusión de éstos.

En el campo sociológico se destacan las producciones mexicanas, las investigaciones y desarrollos en este campo fundamentan la relación de la biblioteca con la sociedad, en relación con las funciones sociales que la institución desempeña. La Universidad Nacional Autónoma de México ha sido un nicho académico relevante para este campo, allí se destaca el trabajo realizado por Felipe Meneses Tello, quien ha desarrollado su indagación en el campo de la biblioteca y su relación con la sociedad. El autor propone discutir cómo se relacionan las bibliotecas con la sociedad, específicamente el rol que estas instituciones han desempeñado como cerebros orgánicos de una cultura civilizada y como reflejo de la cultura de las élites.

Meneses Tello (2005) plantea, partiendo de clásicos bibliotecológicos, la necesidad de la biblioteca como una institución indispensable para la sociedad. Además, realiza un recorrido por las escuelas bibliotecológicas permitiendo identificar en la escuela anglosajona raíces relevantes para la relación biblioteca y sociedad. El análisis de la dualidad bibliotecas y sociedad, es decir, el intento de relacionar el desarrollo de las bibliotecas con el ambiente social, se debe principalmente, según Egan, a la obra de Shera publicada durante el siglo recién pasado.

Asimismo Meneses Tello (2013b) en Bibliotecas y Sociedad: el paradigma social de la biblioteca pública, ahonda y profundiza aspectos teóricos en torno a la relación "bibliotecas y sociedad". En concreto discute cuatro ideas fundamentales relacionadas con el paradigma sociológico de la biblioteca pública: la biblioteca pública como institución social; los postulados sociales de la biblioteca pública; el ethos social de la biblioteca pública y la biblioteca pública como constructora social de la comunidad.

En sintonía con la propuesta de Meneses Tello y las posibles funciones bibliotecarias Urbizagástegui Alvarado, hace un análisis dialéctico que retoma el concepto de habitus de Bourdieu y deja explícito a qué paradigmas sociológicos y políticos responde la biblioteca. El autor se pregunta por el rol que desempeñan las bibliotecas en una determinada sociedad, así como la adopción de determinado punto de vista para la discusión de cuál debe ser el lugar de la biblioteca. Así, el autor retoma las propuestas paradigmáticas básicas de Burrel y Morgan, donde se identifican cuatro paradigmas básicos: objetivista-funcionalista, conflictivo objetivista, interpretativo e interpretativo-conflictivo.

En el espectro pedagógico es representativa la tesis doctoral de la investigadora Orlanda Jaramillo, La biblioteca Pública, un lugar para la construcción de ciudadanía: una mirada desde la educación social (2011), quien a través de una mirada pedagógica indaga sobre el rol social de la biblioteca pública en las prácticas de formación política "en este sentido las prácticas desde la biblioteca pública se plantean en tres aristas: lo público, lo político y lo pedagógico" (p. 140). De este modo, el interés investigador se orientó a la búsqueda de la dimensión política de la 
biblioteca pública a partir de la propuesta de la educación fuera de la escuela y del reconocimiento de la información como un derecho fundamental para el ejercicio de los demás derechos. Para este caso, referentes como Paulo Freire, permiten identificar la acción de participación como el devenir de la acción en igualdad de condiciones y en forma equitativa, para lograr transformaciones en el entorno y en los ciudadanos.

En el campo histórico cabe destacar los aportes realizados por Montoya, Jaramillo y Moncada (2007) de la Escuela Interamericana de Bibliotecología, de la Universidad de Antioquia, en la cual se hace un reconocimiento a los actores de la biblioteca pública en Antioquia en el período 1870-2000, a partir de una metodología cualitativa, con enfoque interpretativo. En esta investigación se resalta el lugar de los actores y aportes al desarrollo de Antioquia en el siglo XX. La investigación histórica hace expresa la memoria de las múltiples realizaciones, de los procesos sociales y de sus múltiples ecos en el presente, en este caso referida al devenir de la biblioteca pública en Antioquia, en esta exploración se resaltan los proyectos ideológicos asociados al desarrollo de la biblioteca pública, no obstante, carece de un análisis sociológico y político en relación con el campo de la biblioteca pública.

Finalmente, se presenta el análisis de los enfoques teóricos en que se enmarcan las investigaciones que hacen parte del estado del arte.

\section{ENFOQUES TEÓRICOS DEL CAMPO BIBLIOTECA Y DESIGUALDAD SOCIAL}

En el presente análisis se retoma la propuesta de Sánchez (1998), para plantear tres posibles enfoques: enfoque empírico analítico, enfoque fenomenológico hermenéutico y enfoque crítico-dialéctico. El análisis realizado se sintetiza en una matriz, presentada a continuación, que narra de acuerdo con cuatro ítems, las diversas propuestas halladas en los documentos en relación con la biblioteca. En el nivel técnico se presentan los instrumentos, técnicas de recolección, organización y tratamiento de datos e información, de acuerdo con cada enfoque. En el nivel metodológico los pasos, procedimientos, maneras de abordar el objeto de estudio o temática estudiada. En el nivel teórico los fenómenos privilegiados, núcleo conceptual básico, autores preferidos. Y en el supuesto gnoseológico las formas de relacionar el sujeto y el objeto. Revela la visión de mundo implícita en la producción científica en relación con el tema de estudio.

\begin{tabular}{|c|c|c|c|}
\hline & $\begin{array}{l}\text { Enfoque empírico- } \\
\text { analítico }\end{array}$ & $\begin{array}{l}\text { Enfoque fenomenológico - } \\
\text { hermenéutico }\end{array}$ & Enfoque crítico- dialéctico \\
\hline Nivel técnico & 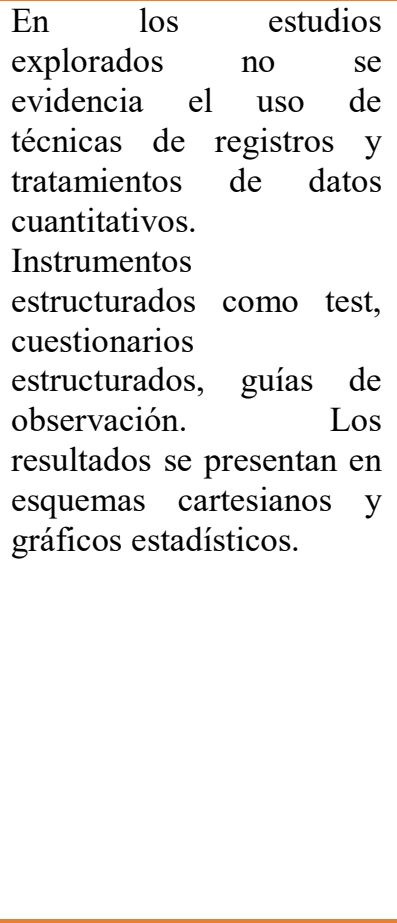 & $\begin{array}{l}\text { En la mayoría de estudios } \\
\text { explorados, se observó el } \\
\text { privilegio de técnicas no } \\
\text { cuantitativas como } \\
\text { entrevistas no estructuradas, } \\
\text { relatos de vidas, estudios de } \\
\text { casos, relatos de experiencias } \\
\text { y otros. Además del uso de } \\
\text { matrices de carácter } \\
\text { cualitativo donde se cruzan } \\
\text { categorías relevantes para los } \\
\text { estudios. Particularmente las } \\
\text { investigaciones de Meneses } \\
\text { Tello (2010, 2012, 2013), } \\
\text { Mendlovic, P. (2014), } \\
\text { Arévalo, J. (2012), } \\
\text { Villaseñor Alonso, I. y Zolla, } \\
\text { E (2012), Jaramillo, O. y } \\
\text { Quiroz, R. (2013), Montoya } \\
\text { Ríos, M.; Jaramillo, O. y } \\
\text { Moncada Patiño, D. (2007). }\end{array}$ & $\begin{array}{l}\text { Utilizan además de las } \\
\text { técnicas implementadas en } \\
\text { un enfoque fenomenológico- } \\
\text { hermenéutico, estrategias } \\
\text { conocidas como } \\
\text { investigación } r \text {-acción, } \\
\text { investigación militante y } \\
\text { algunas formas de } \\
\text { investigación participante y } \\
\text { técnicas historiográficas. En } \\
\text { estas investigaciones se } \\
\text { destacan los trabajos de } \\
\text { Rasteli, A. y Cavalcante, L. } \\
\text { (2014), Riveros, J.; } \\
\text { Salamanca, O. y Moreno, P. } \\
\text { (2012), Toro, A. (2014), } \\
\text { Aranda, R. (2013), } \\
\text { Cuauhtémoc Ochoa, G. } \\
\text { (2013), Ford, B. (2009), } \\
\text { Miñarro Yanini, D. (2009), } \\
\text { Álvarez Zapata, D. (2014), } \\
\text { Civallero, E y Muela Meza, } \\
\text { Z. }\end{array}$ \\
\hline $\begin{array}{l}\text { Nivel } \\
\text { metodológico }\end{array}$ & \multicolumn{3}{|c|}{$\begin{array}{l}\text { Aun cuando no hay estudios con un enfoque positivista, las investigaciones exploradas } \\
\text { poseen poca información en cuanto a su desarrollo metodológico. Los abordajes se realizan } \\
\text { a modo interpretativo y analítico, sin embargo, al momento de presentar cómo se } \\
\text { realizaron los estudios se muestran cortos de fundamentos metodológicos, nombrando }\end{array}$} \\
\hline
\end{tabular}




\begin{tabular}{|c|c|c|c|}
\hline & $\begin{array}{l}\text { Enfoque } \\
\text { analítico }\end{array}$ & $\begin{array}{l}\text { Enfoque fenomenológico - } \\
\text { hermenéutico }\end{array}$ & Enfoque crítico- dialéctico \\
\hline & \multicolumn{3}{|c|}{$\begin{array}{l}\text { como métodos prácticos, estrategias y algunos instrumentos. En el campo de la } \\
\text { bibliotecología, es imperante resaltar que uno de los principales vacíos recae en los } \\
\text { planteamientos metodológicos, los cuales son escasos y pocos conversan con las } \\
\text { tradiciones de las Ciencias Humanas y Sociales. Algunos casos puntuales como Montoya } \\
\text { Ríos, Jaramillo, y Moncada Patiño (2007); quienes narran asumir un enfoque cualitativo } \\
\text { fundamentado en un paradigma interpretativo. O Jaramillo y Quiroz (2013) al narrar que } \\
\text { recurren a un análisis contextualizado según los marcos de la pedagogía y educación } \\
\text { social. Así mismo, Toro Peña (2014) indica hacer uso de una metodología correspondiente } \\
\text { a un análisis de datos narrativos como interpretación de las subjetividades. Y en el caso de } \\
\text { Civallero aun cuando este no enuncia específicamente una metodología hace uso de ideas } \\
\text { que plantean entre líneas una metodología participativa. } \\
\text { No obstante, el tema metodológico en las investigaciones es un tema poco desarrollado y } \\
\text { que requiere ser fortalecido. }\end{array}$} \\
\hline Nivel teórico & $\begin{array}{l}\text { Los desarrollos teóricos } \\
\text { propuestos para realizar } \\
\text { un análisis social de la } \\
\text { biblioteca recurren a } \\
\text { clásicos de la sociología } \\
\text { como Weber. De la } \\
\text { filosofía política como } \\
\text { Althusser. Estos permiten } \\
\text { realizar un análisis de la } \\
\text { biblioteca y sus funciones } \\
\text { como espacios } \\
\text { intencionados } \\
\text { políticamente en los } \\
\text { cuales coexisten diversos } \\
\text { lenguajes políticos en } \\
\text { relación con las prácticas } \\
\text { de lectura y escritura que } \\
\text { se desarrollan en la } \\
\text { biblioteca. }\end{array}$ & 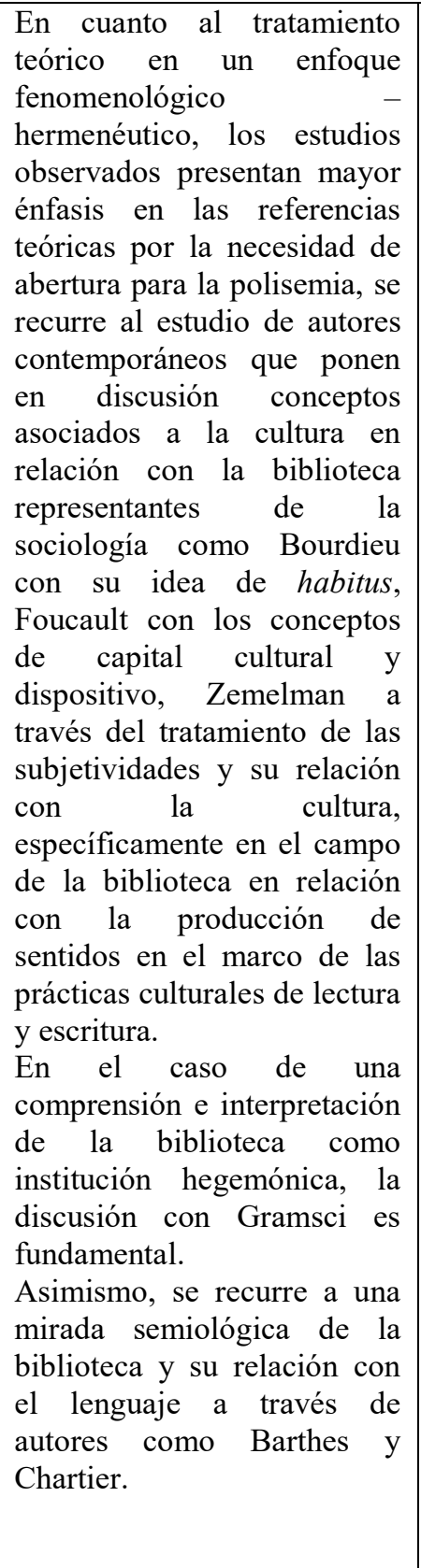 & 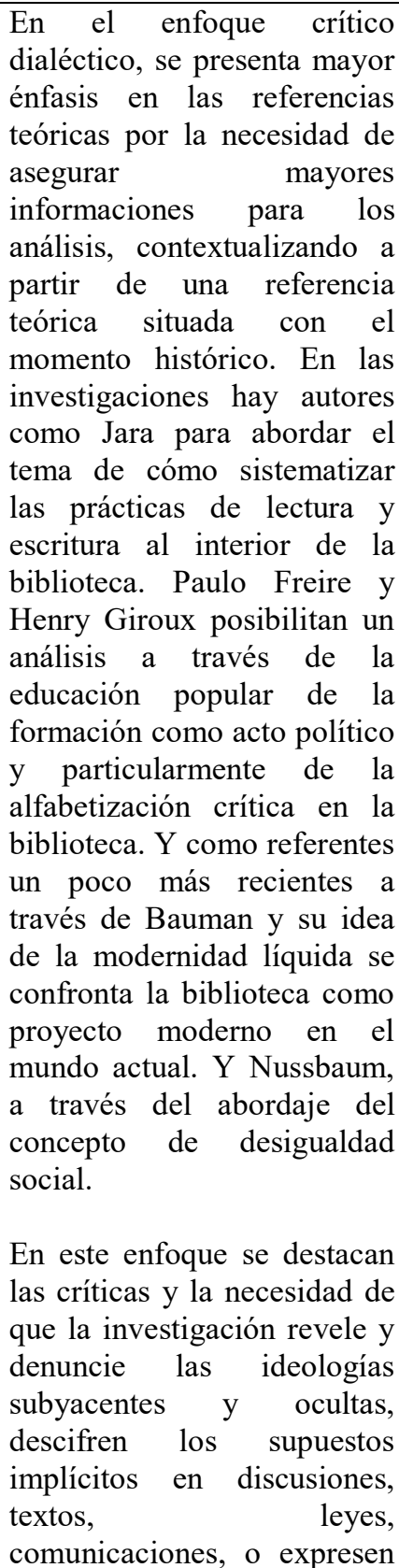 \\
\hline
\end{tabular}




\begin{tabular}{|c|c|c|c|}
\hline & $\begin{array}{l}\text { Enfoque } \\
\text { analítico }\end{array}$ & $\begin{array}{l}\text { Enfoque fenomenológico - } \\
\text { hermenéutico }\end{array}$ & Enfoque crítico- dialéctico \\
\hline & & & $\begin{array}{l}\text { las contradicciones, los } \\
\text { conflictos, los intereses } \\
\text { antagónicos, de la biblioteca } \\
\text { como dispositivo cultural. }\end{array}$ \\
\hline $\begin{array}{l}\text { Supuesto } \\
\text { gnoseológico }\end{array}$ & $\begin{array}{l}\text { Los abordajes empírico- } \\
\text { analíticos privilegian la } \\
\text { objetividad, es decir el } \\
\text { proceso cognitivo } \\
\text { centrado en el objeto en } \\
\text { este caso en la biblioteca. } \\
\text { En este tipo de abordaje } \\
\text { se delimitan y aíslan los } \\
\text { contextos y entornos para } \\
\text { evitar interferencias y } \\
\text { alteración en los } \\
\text { resultados. En este } \\
\text { enfoque teórico la } \\
\text { biblioteca es una } \\
\text { institución de control y de } \\
\text { ordenamiento r para } \\
\text { mantener un modelo de } \\
\text { sociedad instaurado en } \\
\text { ciertas élites. }\end{array}$ & $\begin{array}{l}\text { En el caso del enfoque } \\
\text { fenomenológico- } \\
\text { hermenéutico, el estudio de } \\
\text { la biblioteca se centraliza en } \\
\text { los procesos que vive el } \\
\text { sujeto, privilegiando } \\
\text { subjetividad y por supuesto, } \\
\text { la diversidad de } \\
\text { interpretaciones y sentidos } \\
\text { que el sujeto puede adquirir } \\
\text { en la biblioteca. } \\
\text { En este enfoque se } \\
\text { interpretan los fenómenos a } \\
\text { la luz de sus entornos. El } \\
\text { contexto social y el territorio } \\
\text { son fundamentales. Los } \\
\text { textos tienen sentido en los } \\
\text { contextos. Igualmente las } \\
\text { comunidades son vitales para } \\
\text { la comprensión de la } \\
\text { biblioteca y son estas las que } \\
\text { dan lugar a la institución y } \\
\text { sus propuestas. }\end{array}$ & $\begin{array}{l}\text { La ciencia dialéctica } \\
\text { centraliza el proceso en el } \\
\text { proceso, pretende la } \\
\text { concretud. Las teorías } \\
\text { críticas consideran los } \\
\text { entornos y los contextos. Y } \\
\text { una relación dialógica con } \\
\text { los sujetos. Aquí el supuesto } \\
\text { gnoseológico radica en la } \\
\text { construcción de ideas con las } \\
\text { comunidades y sus } \\
\text { territorios. } \\
\text { En este enfoque toma } \\
\text { relevancia la comprensión de } \\
\text { una biblioteca intercultural, } \\
\text { de un espacio diverso } \\
\text { construido a partir del } \\
\text { diálogo colectivo. }\end{array}$ \\
\hline
\end{tabular}

Tabla IV. Enfoques teóricos - estado del arte.

\section{CONCLUSIONES: TENDENCIAS, HALLAZGOS Y VACÍOS DEL CONOCIMIENTO}

En el apartado de los conceptos previos se observa una tendencia a contar con mayor producción en el tema de bibliotecas y desigualdad social a partir de una comprensión de la biblioteca en relación con la cultura, resaltando el modo en que esta se asocia al mantenimiento de un capital cultural particular. La dimensión política de la biblioteca, a diferencia de la cultural ha sido estudiada en menor medida, sin embargo, en la última década ha tomado una fuerza importante. No obstante, la comprensión de la biblioteca a partir de sus funciones formativas y/o educativas ha sido un tema poco desarrollado. Es así como uno de los vacíos relevantes está ligado con la comprensión pedagógica de la biblioteca, lo cual es de suma importancia al considerarla como institución cultural que incide directamente en las prácticas de lectura, escritura y oralidad en las comunidades. De otro lado, es imperante la comprensión de la biblioteca en el marco de la cultura como un dispositivo cultural, este hecho potencia la biblioteca y sus funciones, y asimismo esta visión en diálogo con las funciones políticas y/o de ciudadanización de la biblioteca implica la comprensión de la institución como un actor político que contribuye directamente a la construcción del tejido social.

El concepto de desigualdad social en el contexto de la biblioteca, aunque previo para realizar la búsqueda bibliográfica, no ha sido un tema tratado explícitamente en la literatura analizada, lo cual permite identificar un vacío 
en la discusión epistemológica respecto al lugar social de la biblioteca. Los estudios de la biblioteca, en relación con la desigualdad social han sido trabajos asociados a indicadores con el acceso a la información, más no con las prácticas bibliotecarias, especialmente las de lectura, escritura y oralidad realizadas en la biblioteca. Los trabajos documentados en este tema, se han referido a la biblioteca como un dispositivo hegemónico, no obstante, han dejado de lado el pensar la potencialidad de la biblioteca como actor contra hegemónico. Esta mirada al tema de la desigualdad ha estado asociada con los lenguajes políticos de la lectura y la escritura y el lugar político de la biblioteca, no obstante, en el campo de la cultura no ha sido desarrollado. Es así como la diversidad cultural, el patrimonio, la memoria no son temas recurrentes al discutir la biblioteca en relación con la desigualdad, esta perspectiva es poco trabajada. La desigualdad social, en el marco de la biblioteca, a partir de un enfoque sociológico y desde los estudios culturales es un tema ausente.

Por último, en este marco analítico es claro el escaso desarrollo de una perspectiva decolonial bibliotecaria, una propuesta desde Latinoamérica no es fuerte y los desarrollos en el campo, en general, se han centrado en retomar categorías modernas/eurocentradas. Las pocas disertaciones en este tema no provienen de estudios superiores, sino de producciones asociadas a la militancia social.

Ahora bien, en los conceptos emergentes se ubica la ciudadanía, el cual fue recurrente en todos los documentos explorados. En esta categoría se han enmarcado las poblaciones, lo cual ha invisibilizado al lector y a las comunidades dando lugar a un ciudadano genérico. Un vacío importante aquí es la escasa discusión de otras posibilidades de comprender a los sujetos que habitan la biblioteca fuera del marco de una ciudadanía asociada con una ideología representativa, lo que implica poner la mirada en poblaciones históricamente desatendidas y su relación con la biblioteca. Una de las principales tendencias con este concepto es la de ubicar al sujeto en el concepto de ciudadanía, independiente de quién sea, de donde provenga y cuáles sean sus particularidades.

Igualmente hay una postura un poco más tímida, sin embargo, existente, de considerar la ciudadanía en la biblioteca como la posibilidad de disidencia de la realidad. Como vacío importante está el trabajo con otras ciudadanías, el cual hasta hace menos de una década ha comenzado. Al igual que en el campo de la biblioteca, en la categoría de ciudadanía es poco trabajada una perspectiva sur ${ }^{6}$ que ponga en discusión su fundamento en relación con una mirada no occidental, la cual se refiere a un ejercicio de construcción epistémica, teórica y metodológica latinoamericana, que posibilite la comprensión de las relaciones de poder/dominio en el espacio-tiempo, así como para la superación de la matriz histórica-colonial de poder y la liberación de los sujetos subalternos. Poniendo en cuestión no solo la linealidad histórica y el evolucionismo paradigmático del pensamiento occidental/moderno sino también la eficacia de las teorías sociales modernas y contemporáneas para dar cuenta de las realidades (socioeconómicas y culturales). También cuestiona su responsabilidad en la reproducción de un conocimiento euro centrado - a través del uso de métodos y categorías modernas, que al cerrarse en la tradición europea occidental, dominante e imperial, ignoran, invisibilizan y subordinan otras epistemes u otros modos de conocimiento y significación.

El principal vacío de los trabajos radica en sus enfoques metodológicos, para lo cual es imperante el fortalecimiento de tareas investigativas que sistematicen su desarrollo juiciosamente, es indispensable que las Ciencias Humanas y Sociales, provean su historia y recursos para fortalecer la práctica investigativa rigurosa y significativa en este tema. Como tendencia, se observa que la mayoría de estudios realizados son de corte fenomenológico hermenéutico, es decir de carácter reflexivo e interpretativo, se requiere fortalecer el nivel crítico dialéctico. Como tendencias se observa un fuerte fundamento sociológico y filosófico para el desarrollo de las investigaciones, el cual va rompiendo con un paradigma positivista y tradicional de la biblioteca.

Uno de los vacíos destacados, es que al ser la minoría de estudios de corte positivista son escasos los estudios que involucren metodología cuantitativa para el análisis de situaciones y políticas públicas en el campo de las bibliotecas, aun siendo conscientes de la relevancia de estos en la construcción de los sistemas de bibliotecas públicas y las políticas asociadas a estos.

De otro lado, la revisión bibliográfica evidencia un relacionamiento interdisciplinar en el cual la bibliotecología se vale de otros saberes para dar cuenta de la incidencia de la biblioteca en la sociedad. Es clara la relación directa con la sociología, la ciencia política y los estudios culturales. La primera, da cuenta de la comprensión de la biblioteca como dispositivo cultural que, inmersa en la sociedad, contribuye a la estructuración del orden social, a través de la instauración del statu quo definido en las esferas políticas del poder. Asimismo, en el campo sociológico las funciones sociales y el rol de la biblioteca como actor cultural son relevantes, puesto que además de contribuciones a un discurso hegemónico puede contribuir a generar espacios de disidencia y resistencia a estos mismos. Este tipo de aportes en el campo sociológico generan una comprensión y discusión referente al modo en que se ha entendido la biblioteca tradicionalmente, a partir de una función utilitaria. La sociología es una posibilidad de superar el paradigma funcional 
y utilitarista de la biblioteca, al concebirla como una institución dinámica, cambiante y con funciones políticas, culturales y educativas esenciales en la construcción de la sociedad. Igualmente, el análisis sociológico crítico de la biblioteca genera una comprensión de la desigualdad social en términos de acceso al capital cultural que conserva cada biblioteca, y como su conservación, recuperación y difusión permiten disminuir o aumentar la brecha en cuanto a la desigualdad existente en términos culturales y sociales.

En el campo de la Ciencia Política se genera la posibilidad de comprender la biblioteca como dispositivo cultural, que contribuye a través de la conservación de un habitus a contextualizar sus recursos y prácticas en lenguajes políticos que influencian directamente en el acceso o restricción de la biblioteca como institución social. Además, se concreta uno de los propósitos relevantes de la institución en el aporte a la construcción de ciudadanía. Este es un campo particularmente imperante para la comprensión de la incidencia de la biblioteca en la desigualdad social, puesto que las acciones de esta, se encuentran ligadas a unos propósitos de mayor envergadura, que generalmente en el caso de la biblioteca pública responde a objetivos estatales.

Ahora bien, el trabajo interdisciplinar de la bibliotecología con los estudios culturales, en la última década ha sido de suma importancia, pues ha sido a partir de este trabajo que se ha logrado generar un reconocimiento a la diversidad cultural en el ámbito de la biblioteca. Este hecho se evidencia en la discusión respecto a las prácticas de cultura escrita que comienzan a generar discusión con la cultura oral. Hecho que tiene un impacto en el modo de organizar las bibliotecas, de pensar sus colecciones y, por supuesto, del trabajo con comunidades no reconocidas hasta hace poco explícitamente en los servicios y programas de la biblioteca. Los estudios culturales, han sido un campo de discusión fértil para pensar en memoria, patrimonio, diversidad en el ámbito bibliotecario. No obstante, la perspectiva desde el Sur está en aras de ser desarrollada.

Los hallazgos y tendencias identificadas en el ejercicio de revisión bibliográfica, permiten identificar que el nexo de bibliotecas y sociedad ha comenzado a explorarse intencionada y fuertemente, lo cual posibilita un nicho académico para la investigación doctoral. Lo cual plantea como retos futuros concretar sus discusiones y desarrollos en política públicas y orientaciones que promuevan explícitamente el rol social de la biblioteca y por tanto su praxis. En el campo sociológico, la categoría de desigualdad social es abordada a través de nociones colindantes a esta como equidad, inclusión, entre otras. Para la investigación, es un reto realizar un relacionamiento, comprendiendo la desigualdad a partir de una visión sociológica que ponga en evidencia la incidencia de la biblioteca en la sociedad. Igualmente el concepto de diversidad cultural, a diferencia de memoria y patrimonio ha sido desarrollado de modo importante. Por tanto, el reto de la investigación es articular las tres categorías y abrir un espacio de discusión donde el patrimonio y la memoria tengan lugar en la biblioteca desde una perspectiva Sur $^{7}$ que reconozca una tradición hegemónica en diálogo con una historia que requiere de otras narraciones para verdaderamente situarse en las problemáticas sociales con que se relacionan con la biblioteca.

\section{NOTAS}

${ }^{1}$ Artículo derivado del estado del arte del proyecto doctoral La incidencia de la biblioteca en la reducción de las desigualdades sociales: el caso del Sistema de Bibliotecas Públicas de la ciudad de Medellín a partir del Acuerdo 079 de 2010, bajo la tutoría de la Doctora Mary Luz Alzate Zuluaga.

2 Para el campo bibliotecológico se usó el Tesauro de Biblioteconomía y Documentación realizado por el Consejo Superior de Investigaciones Científicas, CINDOC. En el campo de las Ciencias Humanas y Sociales se recurrió a ERIC Thesaurus, Thesaurus Brasileiro da Educação y UNESCO Thesaurus.

${ }^{3}$ El habitus es adquirido a través del capital cultural y define al ser que interactúa con sí mismo y con su sociedad, en todo aquello que hace y piensa, de una manera inconsciente. El actuar, en cualquier caso, estará determinado por el habitus: "Nada escapa a la determinación del habitus. Todas las actividades de los seres humanos son determinadas por las estructuras objetivas del mundo en el cual ellos crecen (...). Sin embargo, la ejecución del habitus no es una operación consciente y más bien es inconsciente. Las acciones y pensamientos son generados sin que el actor sea consciente de las operaciones responsables por su pensamiento" (Urbizagástegui, 1992, p. 39).

4 La exclusión, es considerada por Therborn un mecanismo que contribuye a generar desigualdad; particularmente la exclusión bloquea el avance o el acceso de otros y crea una división entre grupos que están dentro y grupos que están fuera. Como mecanismo explicativo, la exclusión debería considerarse más como una variable que como una categoría, como conjunto de obstáculos que dificultan el avance de algunas personas. El conjunto incluiría todo tipo de impedimentos, "techos de cristal" y discriminaciones de diversos tipos, así como puertas cerradas.

5 Therborn plantea otro tipo de desigualdad derivada de la clasificación institucionalizada de los actores sociales, que sitúa a unos arriba y a otros debajo, de cierta sub-ordinación y supra-ordenación. En principio, es una clasificación de los incluidos, aunque también los excluidos pueden ser clasificados (...). Esta desigualdad procede de la jerarquización, y pone de manifiesto la importancia de la organización formal.

${ }^{6}$ En términos de Boaventura de Sousa Santos y su trabajo de epistemologías del sur, al referirnos a una perspectiva sur hacemos referencia a un marco analítico histórico, cultural y político descentrado de occidente. Esta perspectiva es una posibilidad de retomar, conocer y comprender, sucesos, sujetos, territorios, narrativas, relatos, entre otros, que no han hecho parte de la historia eurocéntrica y que de hecho en su mayoría anteceden las historias que conocemos, sin embargo, han estado ausentes debido a prácticas y relaciones coloniales del poder y el saber. 


\begin{abstract}
${ }^{7}$ En palabras de Sousa Santos (2011), la perspectiva Sur es "el reclamo de nuevos procesos de producción, de valorización de conocimientos válidos, científicos y no científicos, y de nuevas relaciones entre diferentes tipos de conocimiento, a partir de las prácticas de las clases y grupos sociales que han sufrido, de manera sistemática, destrucción, opresión y discriminación causadas por el capitalismo, el colonialismo y todas las naturalizaciones de la desigualdad en las que se han desdoblado; el valor de cambio, la propiedad individual de la tierra, el sacrificio de la madre tierra, el racismo, el sexismo, el individualismo, lo material por encima de lo espiritual y todos los demás monocultivos de la mente y de la sociedad -económicos, políticos y culturales- que intentan bloquear la imaginación emancipadora y sacrificar las alternativas. En este sentido, son un conjunto de epistemologías, no una sola, que parte de esta premisa, y de un Sur que no es geográfico, sino metafórico: el Sur anti imperial” (p. 16).
\end{abstract}

\title{
6 BIBLIOGRAFÍA
}

ALEJOS ARANDA, R. Dimensiones de la biblioteca pública: inclusión social desde el sistema nacional de bibliotecas públicas de Perú. Accessbi, 2013, vol. 2, no 2, p. 29-42.

ÁLVAREZ ZAPATA, D. Una región de lectores que crece. Bogotá: CERLALC. UNESCO, 2014.

ÁLVAREZ ZAPATA, D. y NARANJO GIRALDO, G.E. Exploración de las relaciones entre la lectura, formación ciudadana y cultura política: una aplicación a las propuestas de formación ciudadana de las escuelas de animación juvenil, Medellín. Medellín: Universidad de Antioquia, 2003. Disponible en: $<$ http://bibliotecavirtual.clacso.org.ar/ar/libros/colombia/iep/tesis/didier_alvarez/didier_alvarez.pdf $>$. [Consulta: 14 de marzo de 2017].

AlZATE ZUlUAGA, M. y ROMO MORAlES, G. Agendas de gobierno local en plural. Dos casos de estudio en México y Colombia. México: Universidad de Guadalajara, Universidad Nacional de Colombia, 2014.

ARÉVALO, J. El patrimonio como representación colectiva: la intangibilidad de los bienes culturales. Andes, 2012, vol. 23, $\mathrm{n}^{\circ}$ 2. Disponible en: $<\mathrm{http}$ ://www.scielo.org.ar/scielo.php?script=sci_arttext\&pid=S166880902012000200001\&lng=es\&tlng=es $>$. [Consulta: 14 de marzo de 2017].

BARBOSA CHACÓN J.; BARBOSA HERRERA J. y RODRÍGUEZ VILLABONA, M. Revisión y análisis documental para el estado del arte: una propuesta metodológica desde el contexto de la sistematización de experiencias educativas. Investigación Bibliotecológica, 2013, vol. 27, $\mathrm{n}^{\circ}$ 61. Disponible en: <http://revib.unam.mx/ib/index.php/ib/article/view/42815/51240>. [Consulta: 14 de marzo de 2017].

BAUMAN, Z. Daños colaterales: desigualdades sociales en la era global. México: Fondo de Cultura Económica, 2011.

CHUBARIAN, O. Bibliotecología general. Cuba: Técnica, Ed., 1976.

CIVALLERO, E. Bibliotecas indígenas: Un modelo teórico aplicable en comunidades aborígenes argentinas (Tesis de Licenciatura). Universidad Nacional de Córdoba, Córdoba, Argentina [en línea]. Disponible en: $<$ https://www.aacademica.org/edgardo.civallero/118.pdf $>$. [Consulta: 14 de marzo de 2017].

CIVALLERO, E. Escritura y poder [en línea]. Disponible en: $<$ http://tradicionoral.blogspot.com.co/2007/09/escrituray-poder.html $>$. [Consulta: 14 de marzo de 2017].

CIVALLERO, E. Guardianes de la fragilidad: bibliotecas públicas, patrimonio intangible y diversidad cultural. Revista de opinión para el desarrollo de las bibliotecas públicas: Pezdeplata. 2005. Disponible en: $<$ https://www.aacademica.org/edgardo.civallero/56.p >. [Consulta: 5 de enero de 2018].

CIVALLERO, E. La casa de las palabras: un modelo de biblioteca para comunidades indígenas argentinas. 2004. Disponible

en: $<$ https://www.academia.edu/10428478/La_casa_de_las_palabras_Un_modelo_de_biblioteca_para_comunidades_i nd\%C3\%ADgenas_argentinas $>$. [Consulta: 5 de enero de 2018].

CIVALLERO, E. Primitive peoples, civilized peoples: Ideologies underlying documental. (2005) [en línea] Disponible en: <https://www.aacademica.org/edgardocivallero/88.pdf $>$. [Consulta: 14 de marzo de 2017].

CIVALLERO, E. Quebrando el silencio. Bibliotecas, archivos y tradición oral. Códice: Revista de la Facultad de Sistemas de Información y Documentación, 2006, vol. 2, n 2, p. 27-35.

CIVALLERO, E. Voces en el silencio. Biblios, 2006, año 7, $\mathrm{n}^{\circ}$ 25-26. Disponible en: $<$ https://dialnet.unirioja.es/descarga/articulo/2170715.pdf $>$. [Consulta: 14 de marzo de 2017].

CUAUHTÉMOC OCHOA, T. Biblioteca pública y exclusión social en el norte de la Ciudad de México: el caso de Cuautepec Gustavo A. Madero [en línea]. Disponible en: <http://www.redalyc.org/html/325/32528954013/>. [Consulta: 14 de marzo de 2017].

EGAN, M. The library and social estructure. En: GERARD, D. (ed). Library in society. Londres: Clive Bingley, 1978.

FORD, B. Todos son bienvenidos: la Biblioteca Pública como espacio de integración ciudadana. Foro de debate: Biblioteca Pública y Multiculturalidad. Ministerio de Cultura de España, 1999.

FRASER, N. y HONNETH, A. ¿Redistribución o reconocimiento? España: Morata 2006.

GIROUX, H. Los profesores como intelectuales: hacia una pedagogía crítica del aprendizaje. Massachusetts: Paidos, 1988.

GUBA, E. y LINCOLN, Y. Paradigmatic Controversies, Contradictions and Emerging Confluences. En: Handbook of Qualitative Research. United States of America: Sage Publications, 1994. 
IFLA. Manifiesto IFLA / UNESCO por la Biblioteca multicultural. La biblioteca multicultural: portal de acceso a una sociedad de culturas diversas en diálogo. Misión de los servicios bibliotecarios multiculturales [en línea]. Disponible en: <https:/www.ifla.org/files/assets/library-services-to-multiculturalpopulations/publications/multicultural_library_manifesto-es.pdf $>$. [Consulta: 14 de marzo de 2017].

JARAMILLO, O. La biblioteca pública, lugar para la construcción de ciudadanía: una mirada desde la educación social. Medellín: Universidad de Antioquia, 2011.

JARAMILLO, O. y QUIROZ, R. La educación social dinamizadora de prácticas ciudadanas en la biblioteca pública. Educação \& Sociedade, 2013, vol. 34, n 122, p. 139-154.

JARAMILLO, O.; MONTOYA RÍOS, M.; VÉLEZ, C. y MONCADA PATIÑO, D. La biblioteca pública una mirada: desde su génesis y desarrollo: historia y desarrollo de la biblioteca pública en Medellín durante el siglo $X X$. Medellín: Universidad de Antioquia, 2005.

LANDHEER, B. Social functions of libraries. New York: Scarecrow, 1957.

LEVIN, B. The public library as great equalizer. American Libraries, 2000, vol. 31, n 8, p. 50-51.

MENDLOVIC, P. ¿Hacia una "nueva época” en los estudios de memoria social? Revista mexicana de ciencias politicas $y \quad$ sociales, 2014, vol. 59, $\mathrm{n}^{\circ} \quad 221, \quad$ p. $1-23$. Disponible en: $<$ http://www.scielo.org.mx/scielo.php?script=sci_arttext\&pid=S0185-19182014000200013>. [Consulta: 14 de marzo de 2017].

MENESES TELLO, F. Bibliotecas e ideología en el marco del Estado I, 2008c. [en línea]. Disponible en: $<$ http://www.ofaj.com.br/colunas_conteudo.php?cod=360>. [Consulta: 5 de enero de 2018].

MENESES TELLO, F. Bibliotecas e ideología en el marco del Estado II, 2008d. [en línea]. Disponible en: $<$ http://www.ofaj.com.br/colunas_conteudo.php?cod=361>. [Consulta: 5 de enero de 2018].

MENESES TELLO, F. Bibliotecas y democracia: el caso de la biblioteca pública en la construcción de una ciudadanía activa. Anales de Documentación, 2008a, vol. 11, p. 93-127.

MENESES TELLO, F. Bibliotecas y Estado: una teoría politica de las instituciones bibliotecarias. Tesis, grado de Doctor Bibliotecología y Estudios de la Información. UNAM, Facultad de Filosofía y Letras. 2008. [en línea]. Disponible en: < http://132.248.9.195/ptd2008/noviembre/0636036/Index.html>. [Consulta: 14 de marzo de 2017].

MENESES TELLO, F. Bibliotecas y política: el paradigma político de la biblioteca pública. Anales de Documentación, 2013a, vol. 16, $\mathrm{n}^{\circ}$ 2, p. 1-14.

MENESES TELLO, F. Bibliotecas y sociedad: el paradigma social de la biblioteca pública. Investigación Bibliotecológica, 2013b, vol. 27, n 61, p. 157-173.

MENESES TELLO, F. Bibliotecas y Sociedad: reflexiones desde una perspectiva sociológica. Revista Interamericana de Bibliotecología, 2005a, vol. 28, n² 2, p. 117-133.

MENESES TELLO, F. En torno a la visión social bibliotecológica en Bibliotecas y sociedad: interpretación del pensamiento de Judith Licea. Revista Interamericana de Bibliotecología, 2010, vol. 33, n 2, p. 315-333.

MENESES TELLO, F. La carga ideológica en los instrumentos para la organización bibliográfica. Revista General de Información y Documentación, 2013c, vol. 23, $\mathrm{n}^{\circ} 1$, p. 97-131.

MENESES TELLO, F. Las funciones de las bibliotecas, factores de identidad cultural y acción solidaria [en línea]. Disponible en: <http://www.lib.cult.cu/bnjm/foro8/pon4.asp>. [Consulta: 14 de marzo de 2017].

MENESES TELLO, F. Servicios bibliotecarios para grupos vulnerables: la perspectiva en torno de las directrices de la IFLA y otras asociaciones. Informação e Sociedade: Estudos, 2008b, vol. 18, nº 1, p. 45-66.

MENESES TELLO, F. y LICEA DE ARENAS, J. El problema ideológico de la selección-eliminación-destrucción de libros y bibliotecas. Ciencias de la Información, 2005b, vol. 36, n 2, p. 65-71.

MIÑARRO YANINI, D. La Biblioteca Pública como espacio de integración ciudadana. Foro de debate: Biblioteca $\begin{array}{lllll}\text { Pública } & \text { y } & \text { Multiculturalidad } & \text { len } & \text { Disponible }\end{array}$ $<$ http://travesia.mcu.es/portalnb/jspui/bitstream/10421/1221/1/for_301.pdf $>$. [Consulta: 14 de marzo de 2017].

MONTOYA RÍOS, M.; JARAMILLO, O. y MONCADA PATIÑ̃, D. Un reconocimiento a los actores de la biblioteca pública en Antioquia. Medellín: Escuela Interamericana de Bibliotecología, 2007.

MOTA, D.; CAVALCANTE, L. y FEITOSA, L. Informação, memoria e Patrimônio cultural. Revista ABC: Biblioteconomía em Santa Catarina, Florianópolis, 2014, vol. 20, n 2. p. 298-312.

MUDDIMAN, D. et al. Open to All? The Public Library and Social Exclusion. Volume One: Overview and Conclusions. [en línea]. Disponible en: <http://eprints.rclis.org/6283/1/lic084.pdf>. [Consulta: 14 de marzo de 2017].

MUDDIMAN, D. Images of exclusion: user and community perceptions of the public library, En: MUDDIMAN, D., DURRANI, S., DUTCH, M., LINLEY, R., PATEMAN, J. \& VINCENT, J. Open to All? The Public Library and Social Exclusion Volume 3: Working Papers. 2000c, p. 179-189.

MUDDIMAN, D. Public libraries and social exclusion: the historical legacy, En: MUDDIMAN, D., DURRANI, S., DUTCH, M., LINLEY, R., PATEMAN, J. \& VINCENT, J. Open to All? The Public Library and Social Exclusion Volume 3: Working Papers. London: The Council for Museums, Archives and Libraries, 2000a, p. 16-25. 
MUDDIMAN, D. Theories of social exclusion and the public library, En: MUDDIMAN, D., DURRANI, S., DUTCH, M., LINLEY, R., PATEMAN, J. \& VINCENT, J. Open to All? The Public Library and Social Exclusion Volume 3: Working Papers. London: The Council for Museums, Archives and Libraries, 2000b, p. 1-16.

MUELA MEZA, Z. Contradicciones éticas en las responsabilidades sociales en la bibliotecología [en línea]. Disponible en: <http://hdl.handle.net/10760/10591>. [Consulta: 14 de marzo de 2017].

MUELA MEZA, Z. Un acercamiento a las barreras políticas en las bibliotecas públicas mexicanas [en línea]. Disponible en: <http://eprints.rclis.org/6258/>. [Consulta: 14 de marzo de 2017].

NUSSBAUM, M. Creating capabilites: the human development approach. Estados Unidos: Harvard University Press, 2011.

PATEMAN, J. y VICENT, J. Public libraries and social justice. Farnham, Surrey, England; Burlington, VT: Ashgate, 2010.

RASTELI, A. y CAVALCANTE, L. Mediação cultural e apropriação da informação em bibliotecas públicas. Revista eletrônica de biblioteconomia e ciência da informação, 2014, vol. 19, n 39, p. 43-58.

RIVEROS GUERRERO, J.; SALAMANCA, O. y MORENO TORRES, P. Lectura y biblioteca pública: perspectivas sociales en el discurso de la modernidad. Revista Interamericana de Bibliotecología. 2012, vol. 35, n 1, p. 7-16.

SHERA, J. Fundamentos de la educación bibliotecológica. México: UNAM, 1990.

SHERA, J. The library and society. Introduction to library science: basic elements of library service. Littleton, Colorado: Libraries Unlimited, 1976.

THERBORN, G. La desigualdad mata. España: Alianza, 2015b.

THERBORN, G. Los campos de exterminio de la desigualdad. Buenos Aires: Fondo de Cultura Económica, $2015 \mathrm{a}$.

TORO PEÑA, A. Las bibliotecas públicas como instituciones de integración social: Un estudio de caso en la Biblioteca Pública La Peña de BibloRed, en Bogotá (Colombia). Memoria Académica, 2014, vol. 3, n 2, p. $91-101$.

URBIZAGÁSTEGUI, A. El rol de las bibliotecas: un análisis de dos paradigmas sociológicos. Investigación Bibliotecológica, 1992, vol. 6, $\mathrm{n}^{\circ}$ 12, p. 34-41.

VILLASEÑOR ALONSO, I. y ZOLLA MÁRQUEZ, E. Del patrimonio cultural inmaterial o la patrimonialización de la cultural. [en línea]. Disponible en: <http://www.culturayrs.org.mx/revista/num12/VillasenyorZolla_12.pdf>. [Consulta: 14 de marzo de 2017]. 